\title{
SEQUÊNCIA DIDÁTICA: O CONHECIMENTO EMPÍRICO CONTEXTUALIZANDO O ENSINO DE HISTOLOGIA NA EDUCAÇÃO DE JOVENS E ADULTOS (EJA) NO ENSINO MÉDIO
}

\section{Joana Lúcia Alexandre de Freitas}

Escola Estadual de Ensino Médio e Fundamental "Bartouvino Costa”

Linhares, Espírito Santo

E-mail: joana.freitas@hotmail.com

\section{Karina Carvalho Mancini \\ Universidade Federal do Espírito Santo \\ São Mateus, Espírito Santo \\ E-mail: mancinikazinha@gmail.com}

Resumo: Para despertar a vontade de aprender é preciso relacionar os conteúdos com situações cotidianas. Noções básicas em histologia fornecem informações essenciais para a prevenção de doenças e manutenção da saúde. Para tanto, é necessário repensar o ensino e a prática em sala de aula, desenvolvendo ações diferenciadas que despertem a análise e o raciocínio e que promovam uma compreensão dos assuntos ministrados, atendendo as necessidades educacionais dos estudantes. Com o objetivo de lecionar histologia, considerando o senso comum dos alunos, instigando-os a participar das aulas para reconhecer a estrutura celular, histológica, anatômica e fisiológica do corpo humano, esse artigo apresenta as experiências obtidas em uma sequência didática contextualizada, aplicada a 71 alunos da Educação de Jovens e Adultos do Ensino Médio. Nesta prática pedagógica utilizaram-se: recursos audiovisuais aulas práticas e pesquisa elaborada a partir do senso comum dos estudantes.

Palavras-chave: senso comum. educação. tecidos. aulas práticas. sequência didática.

\section{DIDATIC SEQUENCE: EMPIRICAL KNOWLEDGE IN CONTEXTUALIZED HISTOLOGY PEDAGOGICAL PRACTICE WITH YOUNG AND ADULT STUDENTS IN HIGH SCHOOL}

\begin{abstract}
To awaken the desire to learn is necessary to relate the contents with everyday situations. Basic histology notions provide essential information for disease prevention and health maintenance. Therefore, it is necessary to rethink the teaching and practice in the classroom, developing different actions that stimulate the analysis and reasoning and promote an understanding of the subjects taught meeting the educational needs of students. In order to teach histology, considering the students common sense, encouraging them to participate in class to recognize the cellular, histological, anatomical and physiological structure of the human body, this article presents the experiences obtained in a didactic sequence, applied to 71 students of the Youth and Adult Secondary Education. In this pedagogical practice, it was used media, practical classes and research from the common sense of the students.
\end{abstract}

Keywords: common sense. education. tissues. practical classes. didactic sequence.

Recebido em 21/10/2014. Publicado em 30/06/2016. 


\section{INTRODUÇÃO}

De acordo com a LDB (BRASIL, 1996), a Educação de Jovens e Adultos (EJA) destina-se a pessoas que não tiveram acesso ou continuidade de ensino na idade adequada. Por essa razão, nessas turmas, há uma variedade de ideias, ideologias, vivências e culturas.

A EEEFM Bartouvino Costa, onde todo o presente trabalho foi desenvolvido, está inserida na região central da cidade de Linhares (ES, Brasil) e recebe alunos do interior do município, de todos os bairros e do próprio centro da cidade. Esses educandos são trabalhadores rurais, operários, donas de casa, vendedores do comércio, empregadas domésticas e jovens sem experiência profissional. Para completar "o quadro", alguns deles vivem em condição de risco social.

Lecionar para capacitar corresponde a uma série de iniciativas para envolver o estudante no processo de aprendizagem, de forma a auxiliá-lo a perceber a importância dos conhecimentos científicos para a convivência em sociedade e para conhecer a si próprio, como salienta Bock (2008). Nessa ideia, o ensino das diversas disciplinas deve ser pautado na vida e cotidiano dos educandos proporcionando-lhes aprendizagens úteis e aplicáveis, ao invés de pautar-se em livros didáticos que raramente atendem às necessidades educacionais dos estudantes.

De acordo com os PCNEM (BRASIL, 2002), os conhecimentos de Biologia, dentre suas várias finalidades, deve ser útil para compreender os debates atuais e deles participar, visando à perpetuação da própria espécie, a obtenção de alimento, manutenção da saúde e interação com o ambiente para dele extrair a sobrevivência; bem como, entender o funcionamento do próprio organismo. Por isso, faz-se necessário o estudo de Anatomia, Histologia e Fisiologia.

De acordo com Leslie e Hiatt (1997), a Histologia é a anatomia microscópica do organismo, sendo de suma importância para se entender a fisiologia do corpo, porém está reduzida em muitas escolas. Com isso, os estudantes sentem grande dificuldade de compreensão, seja na normalidade ou na patologia da fisiologia humana. Quando a Histologia é trabalhada superficialmente, haverá dificuldade de compreensão em Embriologia, Anatomia e Fisiologia.

Para mudar essa dificuldade de aprendizagem em Histologia, é preciso planejar aulas diversificadas que se alternam ao tradicional método de analise e classificação. Usar de diversas propostas de ensino é o caminho para atingir o público heterogêneo que temos em nossas salas 
de aula. Uma dessas propostas é planejar uma sequência didática, como estratégia para estruturar as etapas pelas quais as aulas e os procedimentos educacionais poderão proporcionar aos alunos o aprendizado esperado.

Dolz e Schneuwly (2004) conceituam a sequência didática como um conjunto de atividades pedagógicas organizadas de maneira sistemática com estrutura lógica dos conteúdos que facilita o direcionamento da aula para o professor e a compreensão do aluno. Também Zabala (1998) afirma que, sequência didática representa um conjunto de atividades e conteúdos ordenados, estruturados e articulados para a realização de certos objetivos educacionais.

No presente trabalho, a sequência didática (SD) aplicada à Histologia para o Ensino Médio teve como principal objetivo a contextualização dos conteúdos a partir do senso comum dos alunos, promovendo discussões em grupo para conhecer o conhecimento empírico deles e assim, relacionar os conteúdos às atividades previstas. Através dessa $S D$ é possível mudar a maneira tradicional de ensinar, baseada apenas no uso de teorias (livro didático) e aula expositiva.

\section{METODOLOGIA}

Esse estudo retrata experiências obtidas no ensino de Histologia contextualizada a partir do conhecimento empírico dos estudantes de EJA do Ensino Médio da EEEMF Bartouvino Costa, localizada no município de Linhares/ES, no primeiro semestre de 2014, com duração de quatro semanas, totalizando oito aulas. Essas experiências são resultantes de uma $S D$ aplicada a três turmas da primeira etapa (19 aET01, 1aET02, 1aET03) ao qual participaram 71 alunos com faixa etária de 18 a 40 anos.

Inicialmente a proposta de contextualização era somente usar temas relacionados à patologia. No entanto, em cada turma de EJA, surgiram dúvidas e curiosidades diferentes daquilo que estava previsto na sequência didática. Tais incógnitas permitiram a ampliação da linha de estudo, com temas como obesidade, drogas, câncer de pele, vitiligo, diferenças na tonalidade da cor da pele entre outros, que auxiliaram na contextualização desse estudo. 


\section{1. $\quad$ As etapas da sequência didática (SD)}

Atividade diagnóstica: Foram organizadas discussões e debates, onde os alunos foram instigados a falar sobre o conceito de Histologia, a curiosidade que eles tinham em relação ao corpo, em relação às doenças e disfunções que ocorrem na pele e demais órgãos, no intuito de conhecer o conhecimento empírico para desenvolver o conteúdo de Histologia.

2ㅇ Aula expositiva dialogada: Foi utilizado Datashow para projetar imagens e micrografias dos tecidos histológicos explicando as estruturas celulares e respectivas funções, bem como responder as dúvidas que demonstraram ter a respeito de cada tecido.

Aula prática: Foram identificados e classificados os tecidos histológicos através de lâminas permanentes e microscópio da escola. Foram utilizadas micrografias para analisar as imagens de alguns tecidos e estruturas celulares que não estavam disponíveis no laminário, como o tecido ósseo e nervoso.

4을 Pesquisa bibliográfica: Foi realizada pesquisa no laboratório de informática da escola. Os alunos pesquisaram sobre assuntos relacionados à histologia, por meio de internet e artigos relacionados ao tema das dúvidas iniciais (doenças, variação na tonalidade da cor da pele, câncer, metabolismo celular, acúmulo de gordura etc.). Também foi sugerido que os alunos pesquisassem o efeito das drogas lícitas e ilícitas sobre os tecidos humanos para ampliar os conhecimentos acerca desse assunto.

50 Exposição da pesquisa: Em cada sala, os alunos se agruparam de acordo com a temática que tiveram interesse em pesquisar e expuseram oralmente aos colegas e à professora as descobertas que fizeram. Após a apresentação, a professora esclareceu os assuntos abordados à luz da Histologia, de modo que eles puderam resignificar o conhecimento empírico que tinham sobre os tecidos histológicos.

6을 Avaliação: Após as apresentações da pesquisa e esclarecimentos, em cada sala, os alunos resolveram atividades sobre os tecidos histológicos como forma de avaliar o aprendizado obtido e auxiliar na fixação dos conteúdos estudados, continuando a exploração da temática. Em aula posterior, ocorreu a correção das atividades e revisão. Depois que as dúvidas foram sanadas, os 
Freitas e Mancini, 2016 - Ensino de Ciências e Matemática

alunos foram submetidos à prova individual e sem consulta com questões discursivas e objetivas. Este instrumento avaliativo teve o intuito de verificar da aprendizagem e o desempenho da SD.

\section{RESULTADOS E DISCUSSÕES}

A maioria dos 25 alunos da turma 1äET01 tinha residência no interior do município e possuía de 18 a 40 anos. Eram adultos interessados em aprender o máximo possível e de forma efetiva. Talvez por timidez, poucos expressaram o senso comum na atividade diagnóstica. No entanto, na aula expositiva dialogada, mais de $50 \%$ da turma participou com perguntas que caracterizavam claramente seus modos de vida. As principais perguntas foram organizadas na tabela 1.

Tabela 1. Principais perguntas feitas pelos alunos da 1aㅡ etapa I no decorrer da aula expositiva dialogada de Histologia.

\begin{tabular}{|c|c|}
\hline \multicolumn{2}{|l|}{ Principais Perguntas } \\
\hline $\begin{array}{l}\text { "Professora, o excesso de suor que tenho é por que tenho muitas glându } \\
\text { Como faço para mudar isso?" }\end{array}$ & sudoríparas? \\
\hline "O excesso de glândulas sebáceas é responsável pelas espinhas?" & \\
\hline $\begin{array}{l}\text { "Por que 'fulano' come, come e não engorda e eu como pouco e ainda engo } \\
\text { células adiposas que ele?" }\end{array}$ & to? Tenho mais \\
\hline "O que eu tenho que comer para aumentar minha quantidade de massa mus & ular?" \\
\hline $\begin{array}{l}\text { "Algumas pessoas têm terminações nervosas na pele para captar temperatu } \\
\text { Por que eu não suportei trabalhar na câmera do frigorífico e meu amigo } \\
\text { boa. Por quê?" }\end{array}$ & $\begin{array}{l}\text { a e outras não? } \\
\text { onseguiu numa }\end{array}$ \\
\hline "Quando envelhecemos os osteoblastos morrem? Por isso o osso fica frágil?" & \\
\hline
\end{tabular}

Fonte: dados da pesquisa.

A turma 1aET02, com 26 alunos, era formada por uma grande quantidade de jovens de 18 a 23 anos de idade, moradores de bairros e periferias do município de Linhares. Poucos trabalhavam ou tinham experiência profissional, gostavam muito de utilizar mídias digitais - inclusive na sala apresentavam muita dificuldade de concentração e de aprender sobre a função e características dos tecidos. Nessa turma, na $1 \underline{a}$ parte da $S D$, poucos manifestaram seu conhecimento empírico e percebeu-se melhor o senso comum deles no decorrer da aula expositiva dialogada. As principais dúvidas estão descritas na tabela 2. 
Freitas e Mancini, 2016 - Ensino de Ciências e Matemática

Tabela 2. Principais perguntas feitas pelos alunos da 1a etapa II no decorrer da aula expositiva dialogada de Histologia.

\begin{tabular}{|c|}
\hline PRINCIPAIS PERGUNTAS \\
\hline $\begin{array}{l}\text { "Professora, a comida gordurosa como chocolate, lanche, churrasco se acumulam em } \\
\text { algumas pessoas e em outras não? Por que tudo que como armazeno, quando faço dieta e } \\
\text { atividade física não consigo emagrecer." }\end{array}$ \\
\hline “Já tomei remédio para controlar a quantidade de espinha, ele mata as glândulas sebáceas?" \\
\hline $\begin{array}{l}\text { "O que as 'bombas', anabolizantes, fazem com as fibras musculares para aumentarem de } \\
\text { tamanho?" }\end{array}$ \\
\hline $\begin{array}{l}\text { "Os neurônios carregam as emoções certo? Por que fumar maconha da o mesmo prazer que } \\
\text { comer alguma comida gostosa ou tomar um tranquilizante?" }\end{array}$ \\
\hline "Quando se fuma maconha, acaba o apetite, por quê?" \\
\hline $\begin{array}{l}\text { "Por que o álcool deixa algumas pessoas tristes, melancólicas e outras alegres e sorridentes? } \\
\text { O álcool bloqueia a ação de alguns neurônios?" }\end{array}$ \\
\hline
\end{tabular}

Os 20 alunos da turma 1aET03 tornavam a aula bem diversificada, com jovens e adultos que tinham de 18 a 30 anos de idade, também residentes nos bairros e periferias do município. Muitos tinham experiência profissional e poucos se prendiam às mídias digitais. De forma geral, participaram ativamente das aulas. No decorrer da 1a etapa da SD (atividade diagnóstica) alguns relacionaram o assunto 'câncer de pele' e 'micoses' como problemas que eles conhecem. Na 2a etapa da $S D$ eles continuaram com suas indagações e as principais estão representadas na tabela 3.

Tabela 3. Principais perguntas feitas pelos alunos da 1a etapa III no decorrer da aula expositiva dialogada de Histologia.

\section{PRINCIPAIS PERGUNTAS}

"Eu vi no Discovery o desenho da pele e achei muito legal, agora estou vendo de novo aqui com a senhora, todas essas estruturas estão presentes em todo mundo? O que acontece com aquele homem que segura fios desencapados com alta voltagem e não toma choque?"

"Professora, quando mais melanócitos tenho mais escura é minha pele?"

"Por que os negros têm menos chance de adquirir câncer de pele?"

“Que tenho de fazer para engordar? Como de tudo, toda hora, e sou magro. Por quê?"

"O que as drogas ilícitas (crack, cocaína, maconha) fazem com os neurônios?"

Fonte: dados da pesquisa. 
Freitas e Mancini, 2016 - Ensino de Ciências e Matemática

Ao analisar as dúvidas dos alunos nas três turmas, foi possível perceber que eles tinham curiosidade em aprender sobre o metabolismo celular e o acúmulo de tecido adiposo, assim como a causa por haver diferentes tons de pele, a relação existente entre as etnias e doenças de pele e ainda sobre o efeito das drogas lícitas e ilícitas sobre os tecidos do organismo humano.

Ao saber dos conhecimentos empíricos e das curiosidades dos alunos, é possível desenvolver estratégias de ensino e formas de intervir em crenças equivocadas que adquiriram no decorrer da vida em sociedade. Personalizar o ensino de modo a seduzir o aluno a interessar-se pelo objeto de estudo é uma forma de apreendê-lo (FREIRE, 1980).

Cativar os alunos da EJA a se interessarem por Histologia se faz mais do que necessário, pelo fato de serem mais desmotivados que os alunos regulares. Quando questionados sobre a razão de tanto desânimo em estudar, alegam, de modo geral, estarem cansados por trabalharem durante o dia, ou por ficar um período longo sem estudar e, às vezes, por serem repetentes e se sentirem incapazes de compreender o que Ihes é ensinado. Sendo assim, a contextualização e a pesquisa vão além do desenvolvimento da aprendizagem. É uma forma de provocar a participação ativa do aluno tirando-o de espectador da aula, para ser coautor. Além disso, o aproxima do mundo científico despertando-lhes o interesse de abstrair a informação que é pertinente à compreensão de seu próprio corpo (LESLIE; HIATT, 1997).

Depois de realizadas as atividades de pesquisa, apresentações e debates, em cada sala, realizou-se revisão sobre os tecidos estudados, como forma de retomar assuntos poucos assimilados, esclarecendo dúvidas, preparando-os também para a prova objetiva e discursiva sobre Citologia (trabalhada anteriormente) e Histologia. No decorrer da presente SD evidenciaram-se as ideias de Duarte (2000), no qual a aprendizagem acontece muito antes do período escolar, desde o nascimento até a idade estudantil, o indivíduo convive com vários sujeitos, tem contato com a língua, costumes e tradições no qual ele interage e abstrai informações para constituir sua visão de mundo e desenvolvimento cognitivo.

Para dar continuidade a esse processo de aprendizagem, o professor precisa conhecer a vida e as ideias de seus alunos para fazer a mediação entre aluno e objeto de estudo (ANTUNES, 2002). Todavia, na maioria das vezes em que a Histologia é lecionada, os professores iniciam suas aulas indo diretamente para o conteúdo abstrato, sem contextualizá-lo, para "não perder tempo" e "ir 
direto ao assunto". Dessa forma, a Histologia fica mal compreendida e provocará dúvidas e desânimo para aprender, surgindo notas baixas e problemas de aprendizagem (LESLIE; HIATT, 1997).

Furth (2007) ressalta que nosso sistema educacional enfrenta uma séria crise de grandes proporções, relacionada a baixos níveis de leitura, altas reprovações escolares, problemas com indisciplinas, desrespeito aos docentes, evasão escolar e delinquência. Para mudar essa realidade, é preciso uma nova filosofia de trabalho e refletir sobre qual é a escola psicológica e socialmente adequada a nossos estudantes e que metodologia utilizaremos para alcançá-la. Saviani (1989) ressalta que é necessário o educador fazer uma reflexão rigorosa sobre os problemas que a realidade educacional apresenta buscando formas de minimizá-la. Um professor de Biologia não deve apenas dominar os conteúdos biológicos, ele precisa conhecer e fazer uso de outras áreas da Ciência para lecionar seus conteúdos como Filosofia e Psicologia, por exemplo.

Aquino (1997) esclarece que para ensinar matemática a João não é necessário conhecer só a matemática, é preciso saber também o conhecimento das leis gerais do funcionamento mental, a própria vida e marcas pessoais de João. Assim também é para a Biologia e qualquer outra disciplina específica da Educação Básica. É preciso encarar o problema de frente, não buscando culpados para o fracasso escolar, e sim pesquisando maneiras de minimizar os problemas educacionais, reformulando a ação, pensando sobre quais objetivos se quer alcançar com essa ação, a forma de potencializar a capacidade de compreensão dos conteúdos e consequentemente, o aprendizado dos alunos (SAVIANI, 1989).

De acordo com Salles (2007), o conhecimento prévio trazido pelos alunos para a sala de aula é a forma como expressam sua visão de mundo, curiosidades e ideias. Se o professor as conhece poderá ter mais facilidades para auxiliar os educando a transformar esses conhecimentos empíricos em científicos, instigando os alunos a desenvolver o pensamento lógico, observação e reflexão, de modo a torná-los capacitados para participar de debates sobre tecnologias, reconhecer e compreender informações biológicas e científicas e ainda, viver interagindo com a natureza sem prejudicá-la.

No ensino de Biologia, os processos mediadores devem ser capazes de conduzir a uma aprendizagem significativa. Para tanto, os conteúdos a serem ministrados precisam ser de 
relevância para o aluno. Aquino (1997) apregoava que a criança aprende a focalizar os atributos mais relevantes a ela e desprezam os menos relevantes. Isso não é diferente com os adultos. 0 aluno adquirirá habilidades e competências em assuntos biológicos quando obtiver plena compreensão da estrutura interna de seu corpo, a relação harmônica que há entre os órgãos e se tornar capaz de assimilar informações biológicas expostas em meios de comunicação de massa como revistas, jornais, filmes, televisão, rádio, entre outros, como expõem os PCNEM (BRASIL, 2002).

No desenvolver da $S D$, ao analisar as tabelas 1, 2 e 3, identificaram-se quais eram as ideias e visões de mundo que os alunos tinham. Verificou-se que as dúvidas estavam relacionadas com o modo de vida, costumes, local onde estão inseridos, profissão, casos de doenças ou disfunção que ocorreram com eles e com familiares.

Por meio da atividade diagnóstica, o regente de classe consegue detectar as necessidades educacionais, dos educandos, e assim, é possível verificar se sua proposta de ensino está de acordo com os anseios deles, caso não esteja, adaptá-la-á de forma a atendê-los. Com essa iniciativa, o professor faz o sujeito estudar pela satisfação de aprender e não pela necessidade que Ihe é imposta (ZABALA, 1998).

Dessa forma, no intuito de aperfeiçoar o ensino de Histologia, a SD foi adaptada nas três turmas de acordo com a especificidade de cada uma. As micrografias usadas na 1aET01 foram trabalhadas com ênfase em metabolismo, benefícios de uma alimentação saudável e equilibrada aliada às práticas esportivas para a manutenção da saúde, ganho muscular e redução de peso. Foram realizadas aulas práticas com lâminas histológicas no laboratório de Biologia e, como proposta de atividade, os alunos relacionaram sua dieta com seu modo de vida e as possíveis consequências desses hábitos para o futuro. Foram ainda instigados a pesquisar sobre osteoporose e hiperidrose para posterior debate.

Com os alunos da 12aET02, as imagens de tecidos histológicos foram contextualizadas com alimentação, metabolismo e obesidade como foi realizado na 1aET1, mas também focando os estragos causados pelas drogas lícitas e ilícitas aos tecidos e órgãos do corpo. Foram realizadas aulas práticas com lâminas histológicas no laboratório de Biologia e para ampliar o conhecimento deles a respeito dos efeitos da maconha, eles analisaram e discutiram um documentário que 
detalha os efeitos devastadores dessa droga nos tecidos celulares. Pesquisaram como os anabolizantes, o crack, cocaína e álcool agem modificando e danificando as estruturas biológicas do organismo, expondo aos colegas de classe o resultado da pesquisa.

Na turma 1äETO3, a Histologia também foi trabalhada contextualizando as estruturas histológicas de cada tecido com as dúvidas, assim como nas outras turmas, porém com foco em obesidade, câncer de pele e formas de evitá-lo, melanina e melanócitos na pele humana e sua relação com a cor da pele. Realizaram aulas práticas com lâminas histológicas no laboratório de Biologia. Como forma de ampliar as informações sobre o assunto, solicitou-se uma pesquisa sobre efeitos de drogas lícitas e ilícitas nos tecidos e órgãos humanos para discussão e debate em sala.

Assimilação de um conteúdo acontece quando há interação entre um organismo e seu meio. A nova informação precisa ter uma importância para o sujeito, interessando-o, motivando-o a conhecê-la e desenvolvendo assim, sua inteligência. "O exercício da inteligência traduz-se pela incorporação de elementos do meio" (AQUINO, 1997, p. 26).

Ao preparar uma boa aula, o professor contextualiza os conteúdos de forma a facilitar a compreensão deles e para dar-Ihes significado. No entanto, o senso comum, as ideias de contextualização do professor podem ser bem diferentes do aluno. Por essa razão, o educador necessita realizar a atividade diagnóstica, seja de forma escrita ou dialogada, para perceber a maneira como vivem, planos de vida, pensamentos, local onde estão inseridos para desenvolver a contextualização dos conteúdos de forma a envolver o aluno no processo de ensino (ZABALA, 1998).

Reforçando essas ideias, Bigge (1977) destaca que o educando precisa sentir-se motivado a aprender. Não adianta apresentar imagens de tecidos histológicos sem relacioná-las com a importância que elas têm na vida do estudante. Quando se motiva os estudantes de maneira enérgica e intencionalmente, eles não apresentam problemas de indisciplina e, se apresentam, é bem reduzida. Se o professor conseguir manter seus alunos motivados ele ganhará a metade da "batalha" de lecionar.

Percebe-se uma aprendizagem significativa quando os fatos científicos se inserem no vocabulário e modo de vida dos estudantes. Memorizar qualquer um é capaz. Refletir, pensar, analisar e julgar 
são competências daqueles que compreendem como funciona a Ciência, porque desenvolveram as competências de observar, pesquisar, questionar, fazer experimentações e expor suas conclusões (BIGGE, 1977).

Os alunos vão expor suas ideias e conclusões, se sentirem à vontade para participar, no decorrer de todo o desenvolvimento da $S D$, não somente na prova. Esta última é um valioso instrumento para verificar a aprendizagem, mas não é o único. Observar e analisar os comentários, as atividades de sala de aula e as ideias dos alunos são também uma forma de avaliar que mudanças significativas que ocorreram com o conhecimento empírico deles, como interagem com as novas informações e se de fato, a aprendizagem está acontecendo ou não (ZABALA, 1998).

Ao analisar os resultados da prova escrita, observou-se um grande número de alunos com notas a cima da média. Nas questões discursivas, boa parte dos alunos discorreu com propriedade do assunto proposto. Em relação a turmas que não tiveram aulas com essa sequência didática (1a etapas de 2013/02), eles obtiveram melhores resultados e consequentemente, mais conhecimentos.

Por razões óbvias, reconhecesse-se que é difícil quantificar a melhoria no aprendizado, pois são alunos diferentes. Entretanto, é notável uma melhora qualitativa nas turmas de 2014/01 que participaram dessa metodologia de ensino, o que comprova que contextualização a partir do conhecimento empírico e pesquisa, são excelentes instrumentos para tornar os conteúdos abstratos significativos para os alunos.

Com resultados tão positivos e significativos, o professor reconhece a importância da SD e passa a utilizar com mais frequência em todas as futuras turmas, adaptando no que for preciso para ensinar com êxito e presteza aos futuros estudantes das primeiras etapas da EJA.

\section{CONCLUSÃo}

Ensinar Histologia somente com base em informações científicas e dados clínicos torna o conteúdo complexo, abstrato, e de certa forma, entediante, surgindo dúvidas, dificuldades de identificação e classificação dos tecidos, e, por conseguinte, memorização de termos técnicos aos quais eles desconhecem o real significado. Em pouco tempo, todas essas informações aos quais tiveram contato tornam-se inconsciente (FREUD, 1917). Portanto, se faz necessário modificar as 
Freitas e Mancini, 2016 - Ensino de Ciências e Matemática

metodologias de lecionar a Histologia, abdicar do método tradicional de identificação e classificação dos tecidos por meio do livro didático, para adotar métodos mais eficazes que despertam o interesse de aprender e conhecer mais sobre os tecidos humanos. O que se defende não é parar com a análise de conceitos e de classificação dos tecidos, mas sim, intercalar essa técnica com outras mais interessantes que poderão ampliar as informações sobre Histologia e que despertem nos alunos a vontade de saber.

Avaliando sistematicamente o resultado da prova e as atitudes dos alunos, percebeu-se uma melhora significativa no aprendizado obtido nas aulas de Histologia, contextualizada a partir do senso comum deles. Não somente com relação à prova escrita, mas também na postura, muitos estudantes relatam que após o estudo realizado passaram a ter mais cuidado com a alimentação, preocupando-se com ingestão de água e em fazer atividades físicas, para manter a saúde, e, também por estética, buscando diminuir a quantidade de tecido adiposo e aumentar a quantidade de tecido muscular.

Diante do sucesso da aplicação desta $S D$, evidencia-se a necessidade de adotar novas metodologias para ensinar Histologia na EJA do Ensino Médio, e a SD pode ser uma delas. Salientando que, o mais importante nesse processo, é elaborar a aula a partir das necessidades educacionais dos alunos e não a partir do livro didático ou da sugestão/opinião do professor.

Diante do que foi exposto, esse artigo comprova que, lecionar de forma contextualizada de acordo com o conhecimento empírico do aluno, e, utilizando-se de uma sequência didática bem planejada e executada de acordo com o modo de vida deles, aumenta consideravelmente a possibilidade dos educandos desenvolverem uma aprendizagem efetiva e durável, aos quais os estudantes utilizaram dentro e fora da escola, transmitindo-as aos familiares e amigos propagando informações científicas que facilitam a vida em sociedade. Estimulando assim, mais educadores a inovar suas práticas pedagógicas por meio da $S D$, para que possam verificar em suas turmas, os resultados positivos dessa metodologia de ensino. 


\section{REFERÊNCIAS}

ALCHORNE, M. M. A.; ABREU, M. A. M. M. Dermatologia na pele negra. Em: Anais Brasileiros de Dermatologia, vol. 83, n. 1, 2008. Rio de Janeiro: Scielo Brasil, 2008.

ANTUNES. C. Vygotsky, quem diria?! Em minha sala de aula: fascículo 12. 4ạ ed. Petrópolis- Rio de Janeiro: Vozes, 2002. $53 p$.

AQUINO, J. G. Erro e fracasso na escola: alternativas teóricas e práticas. São Paulo: Simmus, 1997.

BIGGE, M. L. Teorias da aprendizagem para professores. São Paulo: EPU, 1977.

BRASIL. Senado Federal. Lei de Diretrizes e Bases da Educação Nacional: no 9394/96. Brasília: 1996.

BRASIL, Ministério da Educação. Secretaria de Educação Média e Tecnológica. PCN+ Ensino Médio: Orientações Educacionais complementares aos Parâmetros Curriculares Nacionais - Ciências da Natureza, Matemática e suas Tecnologias. Brasília: Ministério da Educação, 2002.

FREUD, S. (1917[1916-17]). Conferências Introdutórias sobre Psicanálise. Em: FREUD, S. Edição standard brasileira das obras psicológicas completas de Sigmund Freud. V. 16. Rio de Janeiro: Imago, 1990. p. 287-539.

FREIRE, P. Conscientização: teoria e prática da libertação- Uma introdução ao pensamento de Paulo Freire. [Tradução de Kátia de Mello e Silva; revisão técnica de Benedito Eliseu Leite Cintra]. 3a..ed. São Paulo: Moraes, 1980

FURTH, H. G. Piaget na sala de aula. 6ạ ed. - Rio de Janeiro: Forense Universitária, 2006.

HATT, J. L.; GARTNER, L. P. Histologia em Cores. Rio de Janeiro: Guanabara Koogan S.A., 1999. 426p.

MACONHA Substância e Efeitos. Direção: Mônica Nóbrega. Produção: Dr. BRASIL - Médico Toxicologista. Documentário, 8'19". Brasília: 2013., son., color. Disponível em: <youtube.com/watch?v=MwtoAylyHJU>. Acesso em: 28 fev. 2014.

MINHA VIDA, S. A. B. E. Hiperidrose: A doença do suor em excesso. [s.l.]: [s.N.], 2006. Disponível em: <minhavida.com.br/beleza/materias/474-hiperidrose-a-doenca-do-suor-em-excesso>. Acesso em: 6 maio 2014.

ROCK, A. M. B. e outros. Psicologias: uma introdução ao estudo de psicologia. 14. ed. São Paulo: Saraiva, 2008.

SALLES, G.D. Metodologia do Ensino de Ciências Biológicas e da natureza. Curitiba: Ibpex, 2007. 167p.

SAVIANI, D; Autores Associados. Educação: do senso comum à consciência Filosófica. São Paulo: Cortez, 1989.

VIANA, G. M.; MUNFORD, D.; FERREIRA. S. M. e outros. Relações entre teoria e práticas na formação de professores: investigando práticas sociais em disciplina acadêmica de um curso nas Ciências Biológicas. Em: Edu em Ver, Belo Horizonte, v. 28, n. 4, 2012. p. 17-49.

WEISZ, T.; SANCHEZ, A. O diálogo entre o ensino e a aprendizagem. 2. ed. São Paulo: Ática, 2009. 133p.

ZABALA, A. A. Prática educativa: como ensinar. Porto Alegre: Artmed, 1998. 